\title{
EFEITOS DO FECHAMENTO EPISTEMOLÓGICO AO SABER HISTÓRICO NA FORMAÇÃO DOS JURISTAS NOS CURSOS DE DIREITO
}

http://dx.doi.org/10.21527/2176-6622.2020.54.222-231

Recebido em: 20/1/2020

Modificações solicitadas em: 20/4/2020

Aceito em: 26/4/2020

Lucas Melo Borges de Souza

Doutorando em Direito pela Faculdade de Direito de Vitória (FDV). Mestrado em Ciências Criminais e Especialização em Ciências Penais pela Pontifícia Universidade Católica do Rio Grande do Sul (PUCRS). Professor no curso de Graduação em Direito da Faculdade Pio XII. Advogado. http://lattes.cnpq.br/0978022426087092. https:// orcid.org/0000-0003-0737-442X. meloborges@hotmail.com

André Filipe Pereira Reid dos Santos

Doutorado e Mestrado em Sociologia e Antropologia pela Universidade Federal do Rio de Janeiro (UFRJ). Professor no curso de Graduação, Mestrado e Doutorado em Direito da Faculdade de Direito de Vitória (FDV). http://lattes.cnpq.br/9404737943888215. https://orcid.org/0000-0002-8559-1959. afprsantos@gmail.com

\section{RESUMO}

A questão central do presente artigo é a dos efeitos e das decorrências do fechamento epistemológico ao saber histórico na formação dos juristas nos cursos de Direito, tanto no campo do ensino quanto no da pesquisa. Foi utilizada como técnica de pesquisa a revisão de literatura de trabalhos e livros seminais sobre o estado de coisas do ensino jurídico e da pesquisa jurídica nas últimas décadas, bem como a experiência pessoal dos autores na condição de professores universitários em cursos de Direito. Inicialmente são apontados elementos organizadores de uma tradição jurídica normativa e técnica que dá um tratamento superficial, ou que sequer considera os conhecimentos históricos, sociológicos, filosóficos e antropológicos para uma compreensão do fenômeno jurídico na contemporaneidade. Em seguida são examinados alguns efeitos no ensino e na pesquisa jurídica da conjugação de uma tradição jurídica normativa e acrítica com o desapreço ou a indiferença em relação aos estudos históricos e às ciências humanas de uma maneira geral - chamado no texto de senso comum histórico dos juristas, expressão parafraseada de Luís Alberto Warat. O manualismo e a esquematização, o reducionismo metodológico e teórico da pesquisa jurídica e o ethos jurídico técnico e burocrático são alguns desses efeitos. As considerações não estão reduzidas ao final do trabalho. Ao longo do texto são levantados alguns indícios das consequências de uma falta de compreensão crítica do jurista na condição de agente histórico e social inserido em um campo constituído e constitutivo da formação social brasileira.

Palavras-chave: Formação dos Juristas. Saber histórico. Direito.

\section{EFFECTS OF THE EPISTEMOLOGICAL CLOSURE TO HISTORICAL KNOWLEDGE IN THE FORMATION OF JURISTS IN LAW COURSES}

\section{ABSTRACT}

The central issue of the present article it is about the effects and outcomes of the epistemological closure to historical knowledge in the formation of jurists in Law courses, both in legal teaching and legal research. As research technique it was used the literature review of seminal papers and books about the state of affairs of legal teaching and research in the last decades, just as the personal experience of the authors as university professors in Law courses. Initially it is pointed out organizing elements of a normative and uncritical legal tradition that gives a superficial consideration, or doesn't consider at all historical, sociological, philosophical and anthropological knowledge. After that are examined some effects in teaching and research of the conjugation of a normative and uncritical legal formation with the contempt or indifference towards historical studies and human sciences in general - called of historical common sense of jurists, to paraphrase Luis Alberto Warat. Some of the effects are the manualization and schematization of Law, the methodological and theoretical reductionism of legal research and a technical and bureaucratic legal ethos. The notes are not reduced to the conclusion part. Along the article are highlighted some evidences of the consequences of a lack of critical comprehension by the jurists about themselves as an historical e social agent placed a field constituted and constitutive of the brazilian social formation.

Keywords: Formation of jurists. Historical knowledge. Law.

\section{SUMÁRIO}

1 Introdução. 2 Tradição normativa e senso comum histórico dos juristas. 3 "Manualismo" e Esquematização no Direito. 4 Pesquisa e produção de conhecimento nos cursos de Graduação e Pós-Graduação em Direito. 5 O jurista e a decisão judicial no campo do Direito. 6 Considerações finais. 7 Referências. 


\section{INTRODUÇÃO}

Para pensar os efeitos e as decorrências do fechamento epistemológico ao saber histórico na formação dos juristas nos cursos de Direito é necessário, primeiramente, colocar em questão o suporte epistemológico sobre o qual se montou a tradição jurídica ocidental na modernidade. Ou seja, é preciso saber qual o estado epistemológico e prático que domina e forma o modo de pensar e de agir do jurista.

Definitivamente é uma tradição que se faz presente desde a entrada do estudante de Direito na faculdade. Ela moldou e molda de tal forma o ethos jurídico que hoje já ganha o status de algo "natural" no Direito, pois se tornou um componente destituído de qualidade histórica na medida em que passou a habitar o inconsciente jurídico e a formatar a linguagem, o comportamento, a vestimenta, a forma de ver o mundo e a si mesmo, o papel do jurista na sociedade e o hábito de julgar o que diz e o que não diz respeito ao Direito.

A naturalização dessa tradição jurídica apresenta pontos que fazem referência à própria construção do Direito na modernidade ocidental e eles devem ser levados em conta, até porque a sociedade brasileira não está isolada do mundo. O fundamental, porém, é colocar em questão as condições do contexto brasileiro para, assim, explicitar como se deram ou não se deram e como se têm dado as relações entre o Direito e as outras áreas das Ciências Humanas, em especial a História, no ensino jurídico e na pesquisa jurídica, que é o foco de análise do presente artigo.

Por se tratar de um texto limitado pela formatação de artigo científico, são apenas trabalhados alguns apontamentos do fechamento epistemológico do ensino jurídico e da pesquisa jurídica ao saber histórico, o que não impediu os autores de apresentarem, ainda que sem o devido aprofundamento, alguns sintomas da formação dos juristas e dos cursos de Direito no Brasil.

\section{TRADIÇÃO NORMATIVA E SENSO COMUM HISTÓRICO DOS JURISTAS}

Hespanha (1978, p. 9-11) recuperou um dos momentos de construção da tradição jurídica historiográfica (que viria a dominar o campo do Direito) na ascensão dos valores liberais nas sociedades europeias ao longo dos séculos 18 e 19. A relevância dos valores liberais na mudança do campo jurídico estaria, para o autor, no fato de terem funcionado naquele momento na condição de crítica do passado monárquico como um tempo de irracionalidade e violência arbitrária, tanto quanto justificação da luta burguesa contra esse passado e a favor de uma nova ordem. Nesse duplo movimento, o Direito e outras áreas do conhecimento ${ }^{1}$ passaram a exercer um papel de naturalização da nova ordem, com seus valores e suas ideias, a ponto de tentar suspender o quadro vivido do próprio processo histórico e torná-lo uma verdade a-histórica, sem necessidade de questionamentos e reflexões.

Se inicialmente uma das armas de ataque do campo jurídico à ordem monárquica foi a noção de direitos naturais, a pretexto de desmoronar a ordem social desigual vigente com a afirmação de que todos nascem com os mesmos direitos, o caminho posterior às revoluções liberais foi a positivação dos direitos e a crescente tomada de espaço do Direito Positivo, principalmente como forma de limitação do poder do Estado e de especificação de proteções aos cidadãos.

Concomitantemente à positivação dos direitos há a emergência da cientifização do positivismo jurídico nos séculos 19 e 20, que erige uma estrutura discursiva e pretensamente não ideológica de justificação de tal perspectiva, composta de alguns elementos característicos, a exemplo do formalismo, da neutralidade, da autoridade, do progresso e da crença na autossuficiência. Para o campo da história do Direito, o principal efeito do domínio dessa estrutura discursiva no pensamento jurídico moderno foi a depuração do conhecimento das explicações e compreensões históricas, sociológicas, filosóficas e antropológicas que estudam e analisam o funcionamento do fenômeno jurídico nas sociedades, muitas vezes sob o argumento de que o Direito está reduzido à lei e ao Poder Judiciário. Em termos epistemológicos, esse domínio é expresso na desvalorização

\footnotetext{
É interessante lembrar que até o calendário francês foi modificado pela Revolução Francesa, não mais fazendo referência ao nascimento de Cristo. Uma ação que claramente mostrava a vontade de sufocar a concepção do passado com os novos tempos, visto que o calendário era um elemento no qual se via um investimento ideológico preciso e, de certo modo, também revestido de um componente existencial (LE GOFF, 1990, p. 490-491).
} 


\section{Debate}

de problemas teóricos e compreensivos de pesquisa sobre as interlocuções do Direito com as Ciências Humanas em razão da solidificação de problemas de interpretação e aplicação ideal da lei como fonte exclusiva do Direito (HESPANHA, 1978, p. 13-16).

Talvez um dos pontos menos mobilizados e atacados nos cursos de Direito, pelo que pode ser chamado de uma redução da perspectiva epistemológica à técnica jurídica, tenha sido a invisibilização da instrumentalização do Direito como um dos elementos de conservação do racismo mesmo depois da abolição legal da escravidão e do advento da igualdade jurídica com a República. O formalismo, a neutralidade e a ideia de progresso acabam por escamotear o fato de que a lei ainda é um caminho para um encontro entre o passado colonial e escravista com o presente supostamente moderno e não arbitrário.

Em longo prazo, essa redução perspectiva provocou tanto nos estudantes como nos operadores do Direito um senso comum histórico, parafraseando o conceito de Luís Alberto Warat. Foi e é produzido no Direito um discurso que tem assumido o caráter de verdadeiro e que tem delimitado um espaço de validade e de não validade para determinadas explicações e compreensões acerca do papel do Direito e do jurista, da operabilidade e das funções da lei. Como lembra o autor argentino, nesse tipo de discurso circulam representações, imagens, pré-conceitos, hábitos, costumes e estereótipos que reforçam a tecnicidade e o isolacionismo do Direito, ao mesmo tempo que produzem um espaço marginal de não realidade para as entradas históricas, sociológicas, filosóficas e antropológicas no fenômeno jurídico. Na prática, o senso comum teórico dos juristas esconde a instrumentalização do Direito como técnica social e institucional de poder (WARAT, 1994, p. 13-15) e, especificamente, o senso comum histórico dos juristas suspende o Direito da temporalidade, escamoteia as aproximações entre passado e presente e/ou realiza uma leitura anacrônica do passado.

Vários são os sintomas do senso comum histórico dos juristas que atravessam o ensino e a pesquisa: um tratamento da história do Direito pelas diferentes disciplinas jurídicas como uma história de datas, acontecimentos políticos marcantes e aprovação de leis, ao invés de uma história voltada para processos e problemas históricos que estruturam e afetam o funcionamento do Direito na contemporaneidade; a ideia de que o Direito está em constante evolução ao longo do tempo e que o "passado jurídico" é algo que definitivamente ficou para trás; a tentativa de interpretação de institutos jurídicos atuais com base em leituras ideais e despidas da realidade, ou então a partir de uma interpretação advinda de um passado longínquo e que não leva em conta as mudanças e o contexto histórico; a redução das disciplinas e das leituras históricas, sociológicas, filosóficas e antropológicas a um espaço propedêutico nas grades e nas matérias dos cursos de Direito, dificultando um entrelaçamento com as disciplinas e as visões dogmáticas; a recorrência dos tópicos sobre a "evolução histórica" de institutos e conceitos jurídicos em monografias, dissertações e teses, que traçam uma linha das supostas reverberações do instituto do momento presente até o passado mesopotâmico, ${ }^{2}$ grego e/ ou romano, tal como se aí residisse a origem (CARVALHO, 2013, p. 24-29) de todo o Direito ocidental e como se a História fosse uma constante evolução linear, despida de rupturas, diferenças e complexidades; a desconsideração dos conhecimentos históricos, sociológicos e antropológicos na elaboração de políticas públicas e de projetos de lei; a não problematização do papel do jurista para a manutenção ou a crítica de eventuais disfunções da estrutura jurídica.

E a potência do senso comum dos juristas não está somente na marginalização de perspectivas, mas também no esvaziamento da efetividade epistemológica, pois quando é dada alguma consideração aos olhares não estritamente jurídicos no campo do Direito, eles são afirmados apenas na qualidade de conhecimentos introdutórios, sem reflexo na realidade/atualidade da prática jurídica ou algo diverso do Direito por não estar literalmente expresso na lei. As leituras históricas talvez sejam as mais afetadas, principalmente pela ideia superficial de que se trata de algo reduzido ao passado, sem reflexo e presença na realidade jurídica contemporânea.

Nesse fechamento epistemológico do Direito, o único conhecimento considerado válido é o saber técnico dominante produzido pelos juristas, porque em regra é feito pelos pares, por aqueles que são percebidos como os integrantes por excelência da área, bem como por apresentar uma visão conformista e acrítica do

\footnotetext{
Apesar de apresentar o que parece ser uma excessiva visão divisionista dos campos de conhecimento, Luciano Oliveira lembra do hábito nos trabalhos acadêmicos em iniciarem com um capítulo preliminar histórico e, frequentemente, tecerem comentários sobre o Código de Hamurabi, talvez como se essa legislação marcasse o início do Direito ocidental (OLIVEIRA, 2004, p. 143).
} 
Direito, de modo a reafirmar e fortalecer o estado de coisas do campo jurídico. Warat também recorda que a formação da ideia de um posicionamento superior do Direito deriva, em parte, do fato de ser um conhecimento ligado umbilicalmente à formação do Estado moderno e por se manifestar como a racionalidade voltada para a legitimação do monopólio da violência estatal (WARAT, 1994, p. 15-16), o que provoca, em certa medida, uma prepotência do Direito em relação às outras áreas das Ciências Humanas. Inclusive, essa ligação umbilical entre o campo jurídico e o Estado é um aspecto estudado por Sérgio Adorno no que se refere à formação singular do bacharel em Direito, em São Paulo, para a ocupação do corpo burocrático de um Estado liberal e escravista, indicativa também da particularidade de o liberalismo jurídico brasileiro ser moldado e moldar um quadro histórico antidemocrático (ADORNO, 1988).

Entre os efeitos desse fechamento epistemológico, um deles é a criação e consolidação de um abismo não reconhecido ou incompreendido entre a formação social brasileira e a opção pela adoção automática e superficial de teorias sociopolíticas pelo discurso jurídico. Algo que se agrava em um cenário no qual domina a "cultura manualesca", com a citação reiterada entre os próprios juristas de argumentos de autoridade e o afastamento dos problemas da realidade em que o Direito está inserido (BEDÊ; COLÁCIO; NETO, 2017, p. 248-249).

Um exemplo é a teoria do contrato social como ponto de partida para a leitura da formação do Estado brasileiro imperial e republicano, o que deixa implícita a ideia sem correspondência histórica de que o Processo de Independência e a Proclamação da República teriam sido movimentos protagonizados pelas diferentes camadas sociais, em algum tipo de união na qual a vontade geral manifestada abriu mão de parte da liberdade em prol da segurança, primeiro na criação e depois na refundação do Estado Nacional.

Outra leitura jurídica rasa é sustentar o Estado brasileiro na condição de um defensor de direitos e garantias constitucionais - tendo em vista a presença, desde a Constituição Imperial de 1824, de um rol de direitos individuais - sem verificar a (não) materialização na realidade social, visto o Estado brasileiro apresentar uma estrutura histórica de violação e desrespeito desses direitos e garantias.

A visibilização desse abismo pelas explicações e compreensões históricas, sociológicas, filosóficas e antropológicas é o que mostra uma ilusão no campo jurídico, alimentada pelos juristas, de que o Direito é independente da realidade social. Na verdade, o formalismo, a abstração, a neutralidade e a crença na autossuficiência funcionam simbolicamente como dispositivos dissimuladores ou negadores dos conflitos e antagonismos históricos (WARAT, 2002, p. 57-58) sob e entre o Direito e a Política.

Nessas circunstâncias, deve ser sublinhado que se trata de algo que circula não somente no espaço da racionalidade do discurso jurídico, pois atravessa também o domínio afetivo que constitui o estudante e o operador do Direito, no sentido de alcançar até a subjetividade do jurista. O senso comum histórico é um produtor de modos de agir, de pensar, de reconhecer e de ser reconhecido na condição de jurista no Direito, assim como um expediente de clivagem entre o que é e o que não é aceito como ciência jurídica propriamente dita.

No final dos anos 90, Antônio Carlos Wolkmer destacou a presença de uma retomada dos estudos históricos no Direito, que buscavam repensar a tradição normativa de descompasso com as especificidades das experiências sociais e culturais formadoras dos pensamentos, das ideias e das instituições jurídicas no Brasil. ${ }^{3}$ Para o autor, uma compreensão voltada para uma transformação social e humanizadora do Direito brasileiro contemporâneo deve passar por uma interpretação do nosso passado que realce as contradições, permanências, desigualdades e os conflitos que estruturaram a nossa sociedade e que constituem as leis desde o Brasil Colônia, passando pelo Império e chegando na República (WOLKMER, 2002, p. 2-5).

\footnotetext{
3 Antônio Carlos Wolkmer qualifica a tradição normativa dos estudos históricos no Direito como uma prática de mera descrição linearizante e evolucionista das leis, despida de sistematicidade, com o objetivo de conhecer e justificar o passado. Uma tradição que ainda domina o ensino jurídico e que o autor remonta à própria ausência da disciplina de História do Direito na criação dos cursos jurídicos em 1827, somente entrando na grade do curso com a reforma do ensino jurídico em 1891 e já dentro de uma tradição técnico-normativa (WOLKMER, 2002, p. 5).
} 
Assim, os estudos históricos cumpririam um papel de colocação dos problemas sociais, econômicos e políticos sobre os quais o Direito deve se posicionar e enfrentar. Muito além de um saber introdutório, a História do e no Direito deve ser pensada como uma condição de possibilidade para qualquer compreensão presente das formas de funcionamento e dos efeitos do sistema jurídico na sociedade brasileira. Afinal, se uma sociedade não pode se desconectar completamente de sua História, por que com o Direito seria diferente?

Diante de uma formação social estruturada historicamente em termos racistas, antidemocráticos, classistas e patriarcais, a construção no ensino e na pesquisa de um saber jurídico eminentemente brasileiro (saber jurídico brasileiro na acepção de um conhecimento que se volta primariamente para as suas próprias condições históricas e sociais na condição de ponto de partida para pensar a realidade experimentada no cotidiano pelos cidadãos) não pode prescindir de colocar em jogo os encontros e desencontros entre o nosso passado e o presente.

E é importante ressaltar que não se cuida de uma concepção de História na qual o passado do Direito simplesmente dá lições para o presente jurídico, mas sim de que não é possível agir na atualidade e sobre os problemas do Direito sem uma compreensão do passado, do mesmo modo que não é possível olhar para o passado se nada se sabe sobre o presente (BLOCH, 2002, p. 63-67). Embora ainda de difícil reconhecimento, a própria condição do jurista não é outra que não uma condição histórica. Tentar esquecer ou escamotear isso é o mesmo que invisibilizar uma realidade histórica e continuar o caminho de perpetuação da paralisia do Direito e do jurista diante dos problemas sociais.

\section{3 “MANUALISMO" E ESQUEMATIZAÇÃO NO DIREITO}

Na obra "Introdução ao Estudo do Direito", Tércio Sampaio Ferraz Júnior (2003, p. 48) lembra que a noção de Ciência do Direito se transformou na formação universitária, ao longo do século 20, em um saber fechado e formalista, isto é, um produto técnico com a finalidade única de atender o operador do Direito no desempenho de suas funções judiciárias. Assim, o saber jurídico ensinado nos cursos de Direito é cada vez mais despido de seus componentes filosóficos, históricos, sociológicos e antropológicos, consolidando uma visão na qual o Direito é desligado da realidade social e política (LIMA; VARELLA, 2009, p. 121-124).

A formação do jurista nos cursos de Direito tornou-se, em grande medida, um exercício de reprodução e transmissão de um conhecimento posto como oficial, contido quase exclusivamente em manuais de direito e decisões de tribunais, o que acaba por provocar uma dobra do mundo do Direito sobre ele mesmo (não é por acaso que, em regra, os autores dos manuais são advogados, promotores de justiça ou juízes de direito), além de fechar em certa medida o ensino e os juristas para o campo da pesquisa e da produção científica do conhecimento. Como lembra Lenio Streck ao citar Ricardo Guibourg, parte desse muro construído deve-se ao fato de o Direito ser um conhecimento no qual a fala, o discurso e o escrito da autoridade ainda conservam uma considerável força pela simples circunstância de derivarem de uma autoridade (STRECK, 1999, p. 64-68).

Basta consultar planos de curso de disciplinas como Direito Penal, Processo Penal, Direito Civil e Processo Civil, mesmo em faculdades de Direito de cidades e Estados diversos, que se verifica a predominância de manuais de Direito como indicações bibliográficas básicas. E não se pode esquecer da tendência surgida há alguns anos de publicação e utilização de livros esquematizados de Direito, os quais são refratários ao conteúdo reflexivo, de maneira a reduzir uma obra jurídica a um catálogo de informações a serem decoradas.

Uma compreensão das tramas estruturais nas quais o Direito moderno está envolvido é comprimida pela memorização mecânica de conteúdos dogmáticos abstratos. Em resumo, a formação do jurista nos cursos de Direito é moldada por um saber técnico à deriva da história, do social e do político.

Embora não seja o tema específico do presente artigo científico, é preciso colocar em questão o fato de que se está diante de uma industrialização, mercantilização e despolitização do ensino jurídico e que envolve faculdades de Direito, professores, autores de manuais e obras esquematizadas, editoras e livrarias. Um quadro em expansão contínua, com protagonismo dos conglomerados empresariais voltados para o Ensino Superior e do fenômeno da distancialização da vida (GIDDENS, 1991), no presente caso, do ensino e da experiência universitária. 
No que se refere especificamente aos manuais de Direito, ainda que possam ser interpretados por muitos na qualidade de uma prática histórica da ciência jurídica e derivada dos glosadores e comentadores europeus dos séculos 12 e 14 sobre o Direito Romano, o manual tem funcionado como uma das únicas realidades do Direito na formação do jurista.

Mesmo manuais adotados em muitos cursos de Direito e em decisões de tribunais padecem de uma patente falta de consideração para aspectos históricos, sociológicos, filosóficos e antropológicos do Direito moderno. Costumeiramente os manuais começam com tais temas, porém apenas para destacar uma suposta separação entre o objeto de estudo do jurista (a lei) do objeto de estudo das outras áreas das Ciências Humanas (a política, as relações sociais, o passado) ou para sublinhar uma ideia de progressão da sociedade e do Direito passado até o presente com a citação de legislações e/ou linhas de pensamento obsoletas, sem qualquer reflexão sobre possíveis permanências ou mudanças ao longo do tempo.

Ainda que se alegue não ser essa a função primária de um livro de dogmática jurídica, a exclusividade desse material como fonte de conhecimento condiciona no jurista modos de pensar e de agir: um raciocínio mecânico, memorizador e reprodutor do conhecimento jurídico; a naturalização de uma perspectiva acrítica e conformadora do Direito; o não questionamento da posição do jurista no sistema jurídico; uma visão imprecisa da dimensão de implicação dos outros ramos das Ciências Humanas no campo jurídico, entre outros efeitos.

Nesse sentido, o ensino "manualizado" do Direito funciona como uma barreira à entrada e produção de conhecimentos críticos e, simultaneamente, um equalizador do saber jurídico em um quadro de reprodução, irreflexão e acriticidade (BAPTISTA; LIMA, 2014, p. 17-18).

Os manuais esquematizados de Direito incorrem nas mesmas omissões, quando não aprofundam ou sequer citam algo sobre História, Sociologia, Filosofia e Antropologia.

\section{PESQUISA E PRODUÇÃO DE CONHECIMENTO NOS CURSOS DE GRADUAÇÃO E PÓS-GRADUAÇÃO EM DIREITO}

Apesar de não ser um diagnóstico recente, ainda é válida a afirmação da existência de uma prevalência da revisão bibliográfica na pesquisa no Direito (STRECK, 1999, p. 64) e, correlativamente, de uma relutância na adoção de técnicas metodológicas empíricas. O jurista faz pesquisas a partir da revisão de obras de seus pares e com a intenção (in)consciente de se comunicar restritamente com o mundo judiciário. E o gozo do jurista, pesquisador, acadêmico ou não, ocorre quando o seu escrito é citado em alguma decisão de um Tribunal de Justiça.

Essa espécie de reducionismo metodológico da pesquisa no Direito é um componente da "cultura jurídica". Os pesquisadores que se aventuram nos cursos de Graduação e Pós-Graduação em Direito com problemas de pesquisa que escapam da interpretação e aplicação técnica da lei são vistos, em muitos casos, como "menos" juristas ou outsiders do campo jurídico.

É certo que esse diagnóstico não é um estado absoluto da produção de conhecimento e pesquisa no Direito. Samuel Mendonça e Filipe Adaid mostraram em uma pesquisa que, entre os anos de 2004 e 2014, em 60 teses e dissertações envolvidas com a temática do ensino jurídico no Brasil, o ponto de convergência entre os trabalhos foi a utilização de autores que destacam a necessidade de busca por formação crítica na área jurídica mediante um maior destaque aos outros campos das ciências humanas: Horácio Wanderley Rodrigues, Luis Alberto Warat, José Eduardo Faria, Eduardo Carlos Bittar e Roberto Lyra Filho (ADAID; MENDONÇA, 2018).

Quando, no entanto, os trabalhos e as pesquisas que partem de questionamentos históricos, sociológicos, filosóficos e antropológicos sobre o Direito são, em certo grau, avalizados pelo campo jurídico, eles não deixam de carregar o que aparenta ser um título de mera curiosidade para a formação dos juristas ou uma característica de saber introdutório para qualificar o discurso técnico do jurista em suas práticas judiciárias. Assim, o emudecimento da potência desses estudos ainda é a regra.

E as coordenações dos cursos de Graduação e Pós-Graduação em Direito, ao invés de estimularem pesquisas com olhares e perspectivas que vão além da revisão bibliográfica e da leitura técnica da lei, contribuem para a manutenção do establishment epistemológico. Até as bibliotecas das faculdades de Direito refletem o quadro atual ao manterem um acervo constituído em grande parte apenas por obras jurídicas, com pouco espaço para trabalhos de outras áreas das Ciências Humanas. 


\section{Debate}

Não é um acaso a falta de diálogo das faculdades de Direito com as faculdades de História, Ciências Sociais, Filosofia e Letras. O isolacionismo do Direito é um efeito histórico presente no âmbito acadêmico e que aliás se prolonga para além do espaço universitário. Um exemplo notável é o hábito de desconsiderar pesquisas e estudos sobre criminalidade e violência urbana realizados por especialistas das Ciências Humanas e institutos de pesquisa quando da formulação de projetos de lei e de políticas públicas na área criminal.

Também não se pode esquecer do boom de criação de cursos particulares de Direito a partir dos anos $90,{ }^{4}$ que se por um lado possibilitou uma maior abertura do curso de Direito para outras classes sociais e uma ligeira deselitização com o auxílio de programas de financiamento estudantil, por outro lado aprofundou a realidade já existente do abismo entre ensino e pesquisa nos cursos de Direito, além de estabelecer um processo de mercantilização do ensino jurídico.

A produção de conhecimento, ou melhor, a criação de um conhecimento que vá além da tecnicidade da lei e alcance compreensões históricas sobre o fenômeno jurídico não é prioridade nos cursos de Direito, assim como a receptividade e a catalisação dos possíveis efeitos desse conhecimento ainda não está na agenda da formação do jurista.

Uma das conclusões que emergem ao mergulhar na questão da formação dos juristas e da estruturação dos cursos de Graduação e Pós-Graduação em Direito é a premência de revisitar o contexto de início dos cursos jurídicos no Império para perceber a permanência de um ensino excessivamente voltado para uma formação técnica e burocrática (ADORNO, 1988), na qual o jurista deve estar enquadrado na ocupação de funcionário público ou advogado (profissional liberal que também está umbilicalmente conectado ao aparato burocrático do Estado).

\section{O JURISTA E A DECISÃO JUDICIAL NO CAMPO DO DIREITO}

Em um trabalho sobre as possíveis contribuições da metodologia antropológica ao campo jurídico, Roberto Kant de Lima e Bárbara Gomes Lupetti Baptista realizam uma leitura do estado de coisas no campo do Direito, na qual afirmam a existência de fraturas entre o conhecimento dogmático produzido em manuais pelos próprios juristas e as decisões judiciais. Para estes autores, a forma tradicional de construção do conhecimento teórico do Direito por meio de dogmas, de noções abstratas e normatizantes, provocou uma espécie de idealização do campo jurídico, a qual dificilmente encontra reflexo na realidade prática do poder Judiciário, que por sua vez segue valores, ideias e ideais somente correspondentes à dogmática jurídica quando pragmaticamente conveniente e oportuno (BAPTISTA; LIMA, 2014, p. 13-14).

Não se pode esquecer, todavia, que alguns juristas alertam há certo tempo sobre as fraturas entre a dogmática jurídica e as decisões judiciais, bem como sobre as causas e os efeitos dessas rupturas, a exemplo da atitude discricionária e decisionista do juiz de direito ${ }^{5}$ e da adoção por parte da comunidade jurídica de posicionamentos dos tribunais superiores enquanto interpretações aprioristicamente verdadeiras e impassíveis de crítica (STRECK, 2013).

\footnotetext{
Em 2010 o Conselho Nacional de Justiça declarou que existiam no Brasil 1.240 cursos superiores de Direito, enquanto que na China, nos Estados Unidos e na Europa se contabilizavam cerca de 1.100 cursos superiores de Direito. No ano de 2015, 88\% dos 105.317 formados em Direito eram de faculdades particulares (TENENTE, 2017). Atualmente as estimativas chegam a 1.400 cursos superiores de Direito no Brasil.

É comum perceber os traços dessa espécie de encastelamento do posicionamento do juiz de Direito nas próprias decisões judiciais. Talvez um dos julgados mais citados por pesquisadores seja o esclarecimento do ministro Humberto Gomes de Barros sobre o seu voto em Agravo Regimental nos embargos de divergência em Recurso Especial no 279.889/AL: "Não me importa o que pensam os doutrinadores. Enquanto for ministro do Superior Tribunal de Justiça, assumo a autoridade da minha jurisdição. O pensamento daqueles que não são ministros deste Tribunal importa como orientação. A eles, porém, não me submeto. Interessa conhecer a doutrina de Barbosa Moreira ou Athos Carneiro. Decido, porém, conforme minha consciência. Precisamos estabelecer nossa autonomia intelectual, para que este Tribunal seja respeitado. É preciso consolidar o entendimento de que os senhores. ministros Francisco Peçanha Martins e Humberto Gomes de Barros decidem assim, porque pensam assim. E o STJ decide assim, porque a maioria de seus integrantes pensa como esses ministros. Esse é o pensamento do Superior Tribunal de Justiça, e a doutrina que se amolde a ele. É fundamental expressamos o que somos. Ninguém nos dá lições. Não somos aprendizes de ninguém. Quando viemos para este Tribunal, corajosamente assumimos a declaração de que temos notável saber jurídico - uma imposição da Constituição Federal. Pode não ser verdade. Em relação a mim, certamente, não é, mas, para efeitos constitucionais, minha investidura obriga-me a pensar que assim seja" (Voto do ministro Humberto de Barros no AgREG em EREsp no 279.889/AL. Disponível em: www.stj.jus.br. Acesso em: 11 jun. 2019).
} 
Para Roberto Kant de Lima e Bárbara Lupetti Baptista falta ao campo jurídico um autorreconhecimento do abismo entre dogmática e prática judiciária (cada um regulado por seus impérios de opiniões) por meio da perspectiva empírica, de modo a tornar visível a realidade fática do Direito e os possíveis rumos para a construção de um "fazer jurídico diferente" capaz de aproximar o Direito e a sociedade (BAPTISTA; LIMA, 2014, p. 25-27).

A proposta dos autores definitivamente parece ser um exercício fundamental para o questionamento de determinadas práticas do campo do Direito, porém o olhar empírico sobre a realidade judiciária não é suficiente para uma mudança do ethos jurídico vigente, uma vez que o pensar e o agir do operador do Direito faz parte de um processo de formação e conformação iniciado já no primeiro dia de aula nos cursos de Graduação em Direito. O final da faculdade de Direito com a titulação de Bacharel em Direito não marca apenas a conquista de um diploma universitário, também consolida simbolicamente no jurista uma formatação técnica voltada para aceitar acriticamente o papel funcional de uma engrenagem na mecânica judiciária da qual ele agora faz parte.

Dessa maneira, é preciso olhar para o período da formação e inculcação das concepções e ideais que orientam e guiam o jurista como agente nas sociedades contemporâneas. E o questionamento desse estado de coisas passa inicialmente pela entrada de uma reflexão que aponte ao estudante de Direito quais os papéis que o jurista cumpriu e tem cumprido ao longo da história da sociedade brasileira. A partir daí o aluno pode tomar conhecimento que não há apenas um modo de ser jurista e ver outros caminhos abertos pelas pesquisas históricas, sociológicas, antropológicas e filosóficas no Direito.

Caso a formação do jurista e os cursos de Graduação e Pós-Graduação em Direito não passem por uma mudança de paradigma, ${ }^{6}$ os alicerces do ser jurista continuarão estruturados por um pensar-agir jurídico exclusivamente abstrato e normatizante, sem que leituras críticas da História, Sociologia, Antropologia e Filosofia possam fazer mais do que provocar algumas reflexões locais e marginais.

\section{CONSIDERAÇÕES FINAIS}

A depuração da compreensão histórica no Direito contribuiu para um olhar técnico de pura forma. Sem os questionamentos da História no Direito (a falta da perspectiva sociológica, antropológica e filosófica também deve ser levada em conta), o exercício de interpretação e aplicação da lei reduziu-se a um movimento irrefletido ou preenchido de conteúdo pessoal.

A fala do ex-ministro da Justiça Sérgio Moro, ao dizer que o seu projeto anticrime busca "fazer a lei para produzir efeitos práticos e não para agradar professores de Direito Penal” (MARTINS; PERON, 2019), escancara uma das consequências da redução do olhar do jurista a um conhecimento técnico e burocrático: a lei como um espaço de preenchimento de uma vontade autocrática que se recusa, intencionalmente ou não, a enxergar a insuficiência de uma vida normativa para entender a existência nas sociedades complexas da contemporaneidade.

Possivelmente, a redução do saber jurídico a um aspecto técnico e acrítico também tenha contribuído para um efeito rebote sobre o próprio campo jurídico, pois não viabilizou a construção de uma superfície comum de reconhecimento do jurista na condição de agente delimitado por marcadores históricos, sociais e políticos, o que em última instância pode ter alimentado essa sensação de insegurança sentida pelos juristas sobre o que é o Direito, quais funções o Direito tem cumprido ao longo do tempo e qual o papel do jurista, mas também sentida por aqueles que acessam o poder Judiciário ou mantêm algum tipo de contato com o campo jurídico.

\footnotetext{
Não é possível adentrar em outros componentes diretamente relacionados com a temática do presente artigo, mas os autores deixam aqui a observação de que tais questões não são ignoradas: o domínio das cátedras dos cursos de Graduação em Direito por juízes de Direito, promotores de Justiça e advogados, que em regra não "vivem" em tempo integral a experiência universitária (em alguns casos até por falta de tempo) e escolhem o magistério universitário com a finalidade de complementação de renda e/ou aquisição de status; o descompromisso de muitos professores universitários para com uma formação humanística dos juristas; a adoção da aula expositiva como método geral de ensino nos cursos de Graduação em Direito; a busca por instrumentos capazes de desconstruir os juristas já formados por uma concepção técnica e acrítica do Direito; a formação de uma outra concepção do que é o Direito e do que é o operador jurídico pode e deve estar presente no ensino escolar, por meio das Ciências Humanas, em suas devidas proporções quando em comparação com as faculdades de Direito.
} 
Se para os juristas atuantes no poder Judiciário a tônica atual é a situação de lidar com vontades pessoais soberanas sobre o que é o Direito e qual o sentido da lei, ${ }^{7}$ para o jurisdicionado a impressão encontra ligações com o conto "Diante da lei" de Franz Kafka (2013, p. 322-323): a lei é uma porta que está ali para ser acessada por todos e o jurista é o porteiro condutor do acesso à Justiça, mas a lei permanece incognoscível porque é despojada de uma interioridade significativa e comunicativa, somente se manifestando nos bastidores da força e do desejo, no desejo de força expresso na decisão da pura forma legal (DELEUZE; GUATTARI, 1977, p. 65-75).

É óbvio que a proposta do artigo não é suficiente e nem tem a pretensão de conter os parâmetros para uma outra forma de ser do e no Direito. Seria no mínimo arrogância e ingenuidade acreditar que a resposta para os "problemas do ensino e da pesquisa no Direito" poderia estar reduzida a um artigo científico. Esta é uma questão que deve necessariamente envolver debates e ações horizontais dos agentes do campo jurídico, com a participação da sociedade civil, em uma busca comum por mudanças que vão além de experiências específicas e/ou conjunturais, ou seja, com vistas a uma transformação estrutural das concepções e das práticas do e no Direito. Trata-se de um caminho a ser construído ao longo do tempo, muito possivelmente tortuoso, no entanto talvez seja o único capaz de consolidar mudanças radicais e duráveis.

Também são imprescindíveis discussões e propostas para uma desconstrução dos juristas já formados em uma concepção técnica e acrítica do Direito, no sentido de tentar uma aproximação entre essa nova concepção de formação do jurista e a realidade atual da prática judiciária. Uma das propostas que podem produzir efeitos positivos para essa aproximação é a utilização da Antropologia e do método empírico, tal como argumentado por Roberto Kant de Lima e Bárbara Lupetti Batista (2014), de maneira a tornar patente o abismo entre a teoria e a prática jurídica. Caso não sejam tentadas mudanças para os juristas já formados, ampliam-se as chances de choques e sufocamentos de uma outra concepção de formação do jurista, conservando o atual estado de coisas.

A ideia principal dos autores do presente artigo é assentar um espaço de diálogo e debate sobre a temática do fechamento epistemológico na formação dos juristas nos cursos de Direito. Isso foi feito no presente trabalho desde um destaque ao saber histórico em conjugação com ângulos sociológicos, antropológicos e filosóficos sobre os efeitos e as decorrências de um ensino jurídico e de uma pesquisa jurídica reduzida à técnica e ao formalismo acrítico.

\section{REFERÊNCIAS}

ADAID, Felipe; MENDONÇA, Samuel. Tendências teóricas sobre o Ensino Jurídico entre 2004 e 2014: busca pela formação crítica. Revista Direito GV, São Paulo, v. 14, n. 3, p. 818-846, set./dez. 2018.

ADORNO, Sérgio. Os aprendizes do poder: o bacharelismo liberal na política brasileira. Rio de Janeiro: Paz e Terra, 1988.

BAPTISTA, Bárbara; LIMA, Roberto. Como a Antropologia pode contribuir para a pesquisa jurídica? Um desafio metodológico. Anuário Antropológico, Brasília, v. 39, n. 1, p. 9-37, 2014.

BEDÊ, Fayga; COLÁCIO, José Eduardo; NETO, José Maria. A baixa incidência de pesquisa empírica e a cultura manualesca como obstáculos para o desenvolvimento do direito. Direito e Desenvolvimento, João Pessoa, v. 8, n. 2, p. 247-260, dez. 2017.

BLOCH, Marc. Apologia da história ou o ofício de historiador. Rio de Janeiro: Jorge Zahar, 2002.

CARVALHO, Salo. Como (não) se faz um trabalho de conclusão: provocações úteis para orientadores e estudantes do direito. 2. ed. São Paulo: Saraiva, 2013.

DELEUZE, Gilles; GUATTARI, Félix. Kafka: por uma literatura menor. Rio de Janeiro: Imago, 1977.

FERRAZ JR. Tércio. Introdução ao Estudo do Direito: técnica, decisão, dominação. 4. ed. São Paulo: Atlas, 2003.

GIDDENS, Anthony. As consequências da modernidade. São Paulo: Editora Unesp, 1991.

HESPANHA, Antonio. A história do direito na história social. Lisboa: Livros Horizontes, 1978.

KAFKA, Franz. O processo. In: KAFKA, Franz. Franz Kafka: obras escolhidas. Porto Alegre: L\&PM, 2013.

LE GOFF, Jacques. História e memória. Campinas: Editora da Unicamp, 1990.

LIMA, Roberto; VARELLA, Alex. Saber jurídico e direito à diferença: questões de teoria e método em uma perspectiva comparada. In: LIMA, Roberto Kant de. Ensaios de Antropologia e Direito: acesso à justiça e processos institucionais de administração de conflitos e produção da verdade jurídica em uma perspectiva comparada. Rio de Janeiro: Lumen Juris, 2009. p. 89-126.

Streck definiu de forma precisa essa sensação ao sublinhar que "defender a estrita legalidade virou um ato revolucionário" (STRECK, 2019). 
MARTINS, Luísa; PERON, Isadora. Não é fascismo endurecer penas contra crimes graves, diz Moro. Valor Econômico, São Paulo, 4 fev. 2019. Disponível em: www.valor.com.br. Acesso em: 30 maio 2019.

OLIVEIRA, Luciano. Não fale do Código de Hamurabi! A Pesquisa Sociojurídica na Pós-Graduação em Direito. In: OLIVEIRA, Luciano. Sua Excelência o comissário e outros ensaios de Sociologia Jurídica. Rio de Janeiro: Letra Legal, 2004.

STRECK, Lenio. Check list: 21 razões pelas quais já estamos em Estado de exceção. In: Senso incomum. Disponível em: www. conjur.com.br. Acesso em: 29 maio 2019.

STRECK, Lenio. Hermenêutica jurídica $e(m)$ crise: uma exploração hermenêutica da construção do Direito. Porto Alegre: Livraria do Advogado, 1999.

STRECK, Lenio. O que é isto? - decido conforme minha consciência. 4. ed. Porto Alegre: Livraria do Advogado, 2013.

TENENTE, Luíza. Brasil tem mais faculdades de direito que China, EUA e Europa juntos; saiba como se destacar no mercado. G1, Rio de Janeiro, 6 jul. 2017. Disponível em: www.g1.globo.com. Acesso em: 14 jun. 2019.

VOTO do Ministro Humberto de Barros no AgREG em EREsp no 279.889/AL. Disponível em: www.stj.jus.br. Acesso em: 11 jun. 2019.

WARAT, Luís Alberto. Introdução geral ao Direito I: interpretação da lei - temas para uma reformulação. Porto Alegre: Sergio Antonio Fabris Editor, 1994.

WARAT, Luís Alberto. Introdução geral ao Direito II: a epistemologia jurídica da modernidade. Porto Alegre: Sergio Antonio Fabris Editor, 2002.

WOLKMER, Antônio Carlos. História do Direito no Brasil. 3. ed. Rio de Janeiro: Forense, 2002. 